\title{
Legislación y justicia laboral en el “populismo clásico" latinoamericano: Elementos para la construcción de una agenda de investigación comparada
}

Juan Manuel Palacio

Resumen: El trabajo expone las principales hipótesis de una investigación en curso sobre el rol de la legislación y la justicia laboral durante los primeros gobiernos de Perón en Argentina, que sostiene una mirada comparativa con otras experiencias del llamado "primer populismo" (o "populismo clásico") latinoamericano, en particular con los casos de Brasil y México. En la primera parte se pasa rápida revista a "los hechos" en los que se basa esta reflexión, esto es, a los cambios que, en materia legal y judicial en el terreno laboral, se dan más o menos contemporáneamente en cada uno de los países considerados. Son esos hechos, tanto por su contemporaneidad como por su similar contenido, los que invitan a la comparación. En la segunda parte se ensaya una reflexión preliminar sobre las distintas novedades que exhibe la historiografía reciente sobre los populismos "clásicos" latinoamericanos en los países mencionados, tratando de establecer áreas de contacto, así como diferencias y áreas de vacancia. En la tercera se exponen las principales hipótesis de trabajo que guían el proyecto, que si bien pretenden, con los matices que sean necesarios, tener validez para los distintos países considerados, están construidas principalmente en base a la observación de la experiencia argentina.

Abstract: The article displays the main hypotheses of an ongoing research on the role of labor law and justice during the first two governments of Perón in Argentina, which holds a comparative perspective with two other experiences of Latin American "classic" populism -those of Brazil and Mexico. The first section presents "the facts" on which this essay is based, that is, the important changes that took place in a few decades in the fields of labor laws and labor justice in the three countries considered. The second analyzes the recent historiography on these Latin American "classic" (or first) populisms (those of Perón, Vargas and Cárdenas), in order to establish common grounds, as well as differences and lacunae in research agendas. Finally, the third part reflects on a set of hypotheses on the role of law and justice in Latin American populisms which, despite the fact that they draw on the experience of the Argentine case, are meant to be discussed and tested for the other three countries as well.

El presente trabajo expone las principales hipótesis de una investigación en curso sobre los primeros gobiernos de Perón en Argentina, que sostiene una mirada comparativa con otras experiencias del llamado "primer populismo" (o "populismo clásico") latinoamericano, en particular las de Brasil y México. El objetivo general de dicha investigación es analizar el rol que tuvieron tanto la legislación social como muy especialmente los nuevos organismos estatales de resolución de conflictos (los nuevos fueros laborales, las cámaras arbitrales, los organismos de conciliación y arbitraje) en la 
implementación del estado social en América Latina, así como en las formas cotidianas de construcción de hegemonía de estos gobiernos populistas. El estudio se concentra en el ámbito rural de la Argentina -principalmente aunque no exclusivamente en la región pampeana- y analiza las relaciones laborales y contractuales entre terratenientes, arrendatarios, campesinos y trabajadores, apoyándose en una variedad de fuentes documentales, con un eje en los expedientes judiciales de los diversos organismos de conciliación y arbitraje y de los tribunales laborales.

Las hipótesis que se despliegan a continuación tienen un carácter fuertemente preliminar y exploratorio y no pretenden dar una visión concluyente de los problemas que abordan. Por el contrario, por el momento sólo constituyen líneas interpretativas que guían la investigación, originadas en la lectura de trabajos historiográficos recientes sobre estos temas en los tres países considerados y en la pregunta sobre la posibilidad de construir una agenda de investigación comparativa sobre estos temas.

En la primera parte se pasa rápida revista a "los hechos" en los que se basa esta reflexión, esto es, a los cambios que, en materia legal y judicial en el terreno laboral, se dan más o menos contemporáneamente en cada uno de los países considerados. Son esos "hechos", tanto por su contemporaneidad como por su similar contenido, los que invitan hasta podría decirse, exigen- la comparación. En la segunda parte se ensaya una reflexión preliminar sobre las distintas novedades que exhibe la historiografía reciente sobre los populismos "clásicos" latinoamericanos en los países mencionados, tratando de establecer áreas de contacto, así como diferencias y áreas de vacancia. En la tercera, se exponen las principales hipótesis de trabajo que guían el proyecto, que si bien aspiran, con los matices necesarios, a iluminar la experiencia de los distintos países considerados, están construidas principalmente en base a la observación de la experiencia argentina.

\section{LOS "HECHOS"}

Con pequeñas variaciones temporales y con ritmos también sólo ligeramente distintos, durante las décadas de 1930 y 1940, México, Brasil y Argentina produjeron una cantidad inédita de leyes sociales y laborales, que tanto por su cantidad como por su contenido marcaron una clara ruptura con el pasado. Se trató en todos los casos de un conjunto heterogéneo de leyes, decretos y resoluciones, pero también de organismos de aplicación como ministerios, secretarías o departamentos, que si bien en algunos casos no eran enteramente nuevos y tenían antecedentes históricos en décadas anteriores (v.g. Ministerios de Trabajo que antes habían sido Departamentos o Secretarías), constituían un aparato de intervención del Estado sobre las relaciones sociales y contractuales (entre trabajadores y empleadores, entre arrendatarios y terratenientes) de una envergadura inédita. También era inédito el cerrado discurso pro-obrerista, de reivindicación de las clases trabajadoras y campesinas con que los respectivos gobiernos sostenían estas políticas, 
presentándolas como hitos fundacionales en su historia y como parte fundamental de la causa nacional que encarnaban.

Dentro de este conjunto de nuevas instituciones destacan las leyes y los juzgados laborales, ya que el proceso de implementación del "nuevo derecho" significó una batalla particular para estos estados y un aspecto central en su "causa" nacional y "revolucionaria". ${ }^{1}$ Aquí también es necesario aclarar que, si bien algunas leyes protectoras del trabajo, así como algunos organismos estatales de control y regulación, ya existían durante el periodo conservador-liberal anterior (el Porfiriato en México, la Primera República en Brasil y el llamado "orden conservador" en la Argentina), éstas eran en verdad muy escasas y se cumplían en forma limitada. Por el contrario, durante los años treinta y cuarenta del siglo XX (dependiendo del país), no sólo las leyes y organismos anteriores que ya existían adquirieron un impulso nuevo (v.g. normas que pasaron a formar parte de códigos o leyes mayores $u$ organismos que cobraron otra envergadura dentro del Estado) sino que hubo creación de una infinidad de leyes y organismos nuevos, que sin exagerar puede decirse que alteraron buena parte del orden jurídico preexistente.

En cuanto a la legislación laboral, la cronología es clara. México, pionera en la región y en el mundo, define en el artículo 123 de su Constitución de 1917 el inventario de derechos sociales y laborales, con un sentido programático: las décadas siguientes serán las de la progresiva conversión en leyes de esos principios, en un proceso que culmina en la Ley Federal del Trabajo, de $1931 .^{2}$ En Brasil, el gobierno provisional surgido de la revolución de 1930 aprueba diversas leyes laborales a poco de asumir el poder (entre otras, la ley de sindicatos) que luego adquirirán rango constitucional en 1934 -que en su artículo 121 reconoce los sindicatos y enumera derechos sociales y laborales básicos, a la manera del 123 mexicano- proceso que alcanza su climax con la aprobación de la monumental Consolidación de las Leyes del Trabajo (CLT) en 1943, verdadero compendio de las leyes

\footnotetext{
${ }^{1}$ En efecto, el "nuevo derecho" había nacido de la crítica al liberalismo y se sostenía en principios que cuestionaban los fundamentos mismos del orden liberal. En particular, la idea del "contrato de locación" en la que se enmarcaba a las relaciones laborales en los códigos civiles, que ahora se reemplazaba por la idea de un contrato entre partes desiguales que el Estado y la legislación debían proteger. Estas ideas -que en verdad se venían debatiendo en foros jurídicos y políticos en las décadas anteriores- no se van a implementar sin fuertes resistencias del establishment jurídico y político de cada uno de estos países y sólo lo harán luego de mucho debate y conflicto.

${ }^{2}$ El proceso de reglamentación del artículo 123 no se dio sin resistencias y sobresaltos. No pocas de esas resistencias tenían origen en las dirigencias estaduales, que no querían perder la potestad de regulación del trabajo a favor del estado nacional. Los años que van de 1917 a 1931 son testigos de estas marchas y contramarchas de diversos proyectos de ley tendientes a reglamentar el artículo 123. Véase BENSUSÁN, Graciela. "La legislación heredada de las luchas revolucionarias: del constituyente a la Ley Federal del Trabajo". En: MORENO TOSCANO, Alejandra e LEÓN GONZÁLEZ, Samuel: 75 años de sindicalismo mexicano. México: Inst. Nacional de Estudios Históricos de la Revolución Mexicana, 1986 y BENSUSÁN, Graciela. La ley federal del trabajo: una visión retrospectiva. Los intentos de reglamentación local del artículo 123 (1917 - 1929). México: Fundación Friedrich Ebert. (Documentos de trabajo, Fundación Friedrich Ebert, No. 24), 1989; MIDDLEBROOK, Kevin J. The paradox of revolution : labor, the State, and authoritarianism in Mexico. Baltimore \&London: Johns Hopkins Univ. Press, 1995.
} 
laborales brasileñas existentes hasta entonces. ${ }^{3}$ En Argentina, el gobierno surgido del golpe militar de 1943 aprueba diversas leyes sociales y laborales (de asociaciones sindicales, de vacaciones, de regulación del trabajo rural) y luego el primer gobierno de Perón les da nuevo status en leyes más amplias (como la ley 12.921, de 1946, que agrupa, dándoles fuerza de ley, a las diversas regulaciones y decretos de años anteriores, o la Ley de trabajo rural, de 1947) y también rango constitucional en la reforma de la Constitución de 1949.

En todos los casos analizados, estas leyes no sólo dan a los trabajadores derechos y protecciones que eran nuevos (vacaciones y feriados pagos, salarios mínimos, salarios anuales complementarios, derecho a la asociación, jornadas y condiciones de trabajo regulados, entre otros) sino que generan -cierto es, gracias también a una muy efectiva retórica oficial- la sensación de un cambio de época entre los trabajadores, como ha sido ya repetidamente señalado por la historiografía de estos países.

Menos estudiada por dichas historiografías, pero igualmente decisiva, fue la creación de mecanismos y organismos diversos de implementación y control, así como de resolución de conflictos, que diseñaron estos gobiernos para la aplicación de estas leyes. Se trata, por un lado, de la creación de una burocracia especializada dentro del estado nacional para atender la cuestión laboral (supervisando el cumplimiento de la legislación, controlando las asociaciones y sindicatos) y específicamente -dentro o fuera de aquélla- la de organismos especiales para atender el conflicto laboral, que presumiblemente se iba a acrecentar como consecuencia de la implementación de las nuevas leyes.

Aquí nuevamente la cronología es coincidente en los distintos países, llevando México delantera. En 1917 se crea en ese país la Dirección de Trabajo dentro de la Secretaría de Industria, Comercio y Trabajo ${ }^{4}$, que se convierte en Departamento de Trabajo Autónomo en 1932 y en Secretaría de Trabajo en 1940. Por otra parte, ya en el citado artículo 123 de su Constitución de 1917 se prevé el mecanismo de las Juntas de Conciliación y Arbitraje con representación tripartita para la resolución de conflictos laborales, primer antecedente de la justicia laboral en ese país. ${ }^{5}$ Además de atender el conflicto, estas Juntas tenían funciones decisivas, como el reconocimiento oficial de sindicatos, la sanción de los convenios colectivos (o "contratos-ley") de un determinado sindicato con la industria y el establecimiento del salario mínimo. Muy disputadas por empleadores y en general por las

\footnotetext{
${ }^{3}$ BARROS BIAVASCHI, Magda. O Direito do Trabalho no Brasil - 1930/1942: A construção do sujeito de direitos trabalhistas. Tese de doutorado, Universidade Estadual de Campinas, 2005; FRENCH, John D. Drowning in laws: labor law and Brazilian political culture. Chapel Hill: Univ. of North Carolina Press, 2004.

${ }^{4}$ Existía un Departamento Nacional del Trabajo desde 1911, en el mismo estilo y espíritu "reformista" de los que también existían en Brasil y Argentina en la década de 1910.

${ }^{5}$ Aunque en verdad éstas ya existían en diversos estados desde 1910. Véase MIDDLEBROOK, Op. cit; DE LA CUEVA, Mario. Derecho mexicano del trabajo. México: Porrúa, Quinta edición (1a 1949), 1963; BESUNSÁN, Graciela. La ley federal... Op. cit.; MONTES DE OCA NAVAS, Elvia. Política laboral y corporativismo en el Estado de México 1934-1940. Zinacantepec: El Colegio Mexiquense \& Inst. Tecnológico y de Estudios Superiores de Monterrey, 2000; SUAREZ-POTTS, William J. (2009): "The Mexican Supreme Court and the Juntas de Conciliación y Arbitraje, 1917-1924: The Judicialisation of Labour Relations after the Revolution". En: Journal of Latin American Studies No. 41, 4, 2009, pp. 723-755.
} 
burguesías (y a veces los gobiernos) locales, estos mecanismos de resolución de conflicto van a ser fortalecidos por un fallo de la Corte Suprema de 1924 -que da a sus decisiones fuerza de ley ${ }^{6}$ - y luego por la Ley Federal del Trabajo de 1931, que crea un Sistema Nacional de Conciliación y Arbitraje, en manos del Poder Ejecutivo (con Juntas subsidiarias en el nivel estadual y municipal), para resolver conflictos tanto colectivos como individuales. ${ }^{7}$ Este sistema perdura en México hasta el día de hoy en manos del Poder Ejecutivo.

En Brasil, el Departamento de Trabajo, que existía desde 1918, fue transformado por el gobierno revolucionario de Vargas en Ministerio en 1931. Asimismo, en 1932 se crean por decreto las Juntas de Conciliação e Julgamento para atender a los conflictos individuales de los trabajadores, así como las Comissões Mistas de Conciliação, para los colectivos. La Constitución de 1934 preveía en su artículo 122 la organización de una Justicia del Trabajo, de la misma manera que la de 1937, que da origen al Estado Novo, su creación como órgano administrativo dentro del Ministerio de Trabajo, algo que se implementa por decreto recién en 1940. Seis años más tarde, la JT se convierte en un fuero nuevo dentro del Poder Judicial. ${ }^{8}$

En Argentina, el gobierno de la Revolución de Junio de 1943 transforma en ese año el Departamento de Trabajo (que existía desde 1912) en Secretaría de Trabajo y Previsión, y el gobierno de Perón lo convierte en Ministerio en 1949. Por otro lado, un decreto del gobierno militar de 1944 dispone la creación de los Tribunales del Trabajo a nivel nacional, organizándose los de la Capital Federal en 1945 y los de la provincia de Buenos Aires en 1947. ${ }^{9}$ En ese mismo año, la ley 13.020, sobre Trabajo Rural, crea en el ámbito del Ministerio de Trabajo la Comisión Nacional de Trabajo Rural, destinada a entender en todo lo concerniente a la regulación del trabajo rural y a intervenir ("en procura de una conciliación") en las controversias que pudieran surgir por la aplicación de las leyes laborales. La Comisión estaba constituida por dos delegados del Ministerio de Agricultura, un representante de los obreros y otro de los patronos y su presidencia ejercida por un funcionario de la Secretaría de Trabajo. ${ }^{10}$

Este rápido repaso de la cronología de la creación de leyes sociales e institutos de protección y regulación del trabajo en México, Brasil y Argentina revela algunas similitudes en los procesos y sugiere unas reflexiones generales:

1. La creación de organismos de implementación de las nuevas leyes laborales y de control del trabajo fue tan fundamental como la misma aprobación de leyes sociales y parte inseparable de un único proceso. Dentro de estos nuevos institutos, fueron clave aquellos

\footnotetext{
${ }^{6}$ SUAREZ-POTTS, William J. Op. cit.

${ }^{7}$ El sistema federal había sido creado por el presidente Calles en 1927 y es incluido y ampliado en la LFT.

${ }^{8}$ VARUSA, Rinaldo J. Trabalho e legislação: experiências de trabalhadores na Justiça do Trabalho (Jundiaí - SP, décadas de 40 a 60). Dissertation, Pontifícia Universidade Católica/Sao Paulo, 2002; BARROS BIAVASCHI, op. cit.

${ }^{9}$ El resto de las provincias fueron organizando los suyos en los años subsiguientes.

${ }^{10}$ La ley disponía que el nuevo instituto se organizara en diferentes "comisiones paritarias" locales a lo largo de todo el país, con la función de regular las condiciones y jornadas de duración del trabajo rural así como de fijar anualmente los salarios para cada actividad. También cumplían funciones de policía del trabajo en colaboración con la Secretaría de Trabajo y Previsión, pudiendo levantar actas de infracción.
} 
diseñados para entender en los conflictos que generara la nueva legislación (juntas de conciliación, justicia del trabajo, etc.)

2. Es necesario comprender la creación de organismos específicos para atender la cuestión laboral y contractual dentro del proyecto más amplio de profunda transformación de las estructuras del Estado por parte de estos gobiernos llamados "populistas". Esta tenía como objetivo no sólo mejorar su eficacia para la regulación, el control y la planificación -a través de procesos más estrictos de selección e ingreso y de la formación de sus cuadros técnicos en cursos de capacitación- sino también fomentar un espíritu de cuerpo y un sentido de misión afín a la "causa" nacional en los agentes burocráticos. ${ }^{11}$

3. Este acrecentamiento de la burocracia del estado nacional era coherente con la intención de estos gobiernos de ejercer un control centralizado del país desde el gobierno central. Existe, detrás de la creación de organismos nuevos -conjuntamente con la intención de hacer más eficiente el Estado- la vocación de "conquistar" el territorio nacional, de nacionalizar el imperio de la ley, de garantizar la efectiva implementación de las leyes. Aunque con variaciones en los distintos países considerados, esta pretensión provocó no pocos conflictos entre el estado nacional y los poderes locales (ya fueran estos económicos, gubernamentales o burocráticos).

4. La similitud en cuanto a la variedad y el contenido de las leyes y organismos, como así también su contemporaneidad en los distintos países, sugieren que éstas no se concibieron aisladamente en cada país, sino que eran el fruto de un clima de época, de influencias teóricas, fuentes jurídicas, experiencias y tradiciones comunes. También, que los contactos y la circulación de esas ideas deben haber sido fluidos entre estos países y las experiencias mutuamente conocidas y compartidas (a nivel académico y universitario, pero también a nivel de los funcionarios de la alta burocracia).

\section{LA HISTORIOGRAFÍA}

La historiografía latinoamericana de las últimas décadas ha vuelto su mirada sobre el momento de construcción de los estados sociales o "de bienestar" a mediados del siglo XX, con una fuerte impronta revisionista. Así, se han multiplicado trabajos que abordan aspectos escasamente estudiados previamente, como la dimensión regional y local del fenómeno

\footnotetext{
${ }^{11}$ Entre outros, BERROTARÁN, Patricia; JÁUREGUI, Aníbal e ROUGIER, Marcelo (Eds.) Sueños de bienestar en la Nueva Argentina. Las políticas públicas durante el peronismo, 1946-1955. Buenos Aires: Imago Mundi, 2004; BERROTARÁN, Patricia. "Educar al funcionario: 'de la frialdad de las leyes a las innovaciones doctrinarias' (Argentina 1946-1952)”. En: Nuevo Mundo Mundos Nuevos, 2008. URL: http://nuevomundo.revues.org/36602 (16/06/2008); FERREIRA, Jorge. Trabalhadores do Brasil. O imaginário popular. Rio de Janeiro: Fundação Getulio Vargas, 1997.
} 
"populista", la conformación y el funcionamiento de la nueva burocracia estatal o algunas áreas específicas de políticas públicas -más allá de la tradicional mirada sobre la política laboral y obrera, que concentró casi toda la atención en el pasado- proponiendo una imagen del fenómeno mucho más fragmentada que la que sostenían las visiones clásicas.

Logran así desarmar el sentido común imperante sobre esos regímenes (v.g., que se sustentaban en un liderazgo compacto y verticalista; que articularon un intervencionismo eficaz de la mano de una burocracia omnipresente; que ejercieron un control político férreo y centralizado; y que encarnaron una verdadera "revolución" que rompió drásticamente con la tradición y la cultura política anterior) y ponerlos en caja con la historia, reinterpretando todas las supuestas novedades que trajeron en términos de continuidades con el pasado. En particular, han revisado la imagen de unas clases subalternas pasivas y cooptadas fácilmente por líderes de perfil "carismático", para indagar en la racionalidad del apoyo crítico y condicional que esos sectores dieron a estos gobiernos en momentos históricos precisos. ${ }^{12}$

Entre las novedades que exhiben estas historiografías se cuentan una importante renovación de los temas de investigación, así como de las miradas sobre temas tradicionales, con aportes desde perspectivas historiográficas diversas, como la historia cultural, la historia del arte, los estudios migratorios, la historia de las ideas, sin que ninguna reclame una visión hegemónica sobre el tema. También exhiben cambios en las escalas de análisis -con una marcada predilección por los estudios regionales y locales por sobre los nacionales- y en las perspectivas teóricas, con una notable preferencia por interpretaciones "culturalistas", que resaltan la esencial inestabilidad y ambigüedad del mundo social y en particular del Estado y privilegian el estudio de las prácticas cotidianas de los actores sociales. El resultado es un mosaico interpretativo de una gran riqueza y heterogeneidad que simultáneamente propone una mirada sobre el fenómeno de los "populismos clásicos" mucho más fragmentada (los nuevos trabajos prefieren ya no hablar del "peronismo", "cardenismo" o "varguismo" sino cada vez con más frecuencia de "peronismos" o "cardenismos", en plural) que la que proponían las visiones tradicionales sobre estos regímenes.

Por último, esta renovación estuvo íntimamente ligada a la de los instrumentos utilizados para realizar estos originales abordajes. En efecto, las fuentes primarias también se han enriquecido, sumándose ahora a las más tradicionales (la prensa, las proclamas de los sindicatos, los debates parlamentarios, los textos legales, etc.) herramientas como los programas de los cursos de capacitación de la burocracia (y los textos de los manuales que se usaban allí); las trayectorias burocráticas, muchas veces reconstruidas a través de entrevistas; la iconografía, la arquitectura, y la fotografía; las cartas que los trabajadores escribían a los presidentes con demandas cotidianas, entre muchas otras.

Muy especialmente, el análisis de los expedientes judiciales (de la justicia laboral, de las juntas de conciliación, etc.) han sido fundamentales para estos revisionismos, dada la potencialidad que tienen esos archivos para esclarecer motivaciones y modalidades del

\footnotetext{
${ }^{12}$ PALACIO, Juan Manuel. "El primer peronismo en la historiografía reciente: nuevas perspectivas de análisis". En: Latinoamericana (Berlin), 39, 2010, pp. 255-266.
} 
conflicto social, así como para estudiar las culturas legales que gobiernan una sociedad (entendidas como conocimientos y como prácticas y usos de la ley y las instancias judiciales) y para asomarse a las experiencias de los trabajadores frente al estado. ${ }^{13}$ En particular, como lo han demostrado algunos trabajos de la historiografía brasileña reciente, los expedientes de la justicia laboral resultan clave para evaluar continuidades y cambios como consecuencia de la implementación de las leyes laborales durante los gobiernos "populistas", así como para brindar un panorama más complejo que el que proporcionaba la imagen de una clase trabajadora cooptada por dichos regímenes. ${ }^{14}$

\section{La historiografía argentina reciente sobre el primer peronismo}

En las últimas décadas, la historiografía argentina, luego de muchos años de desatención, ha "revisitado" los años de los primeros gobiernos peronistas (rebautizándolos, además, como los del "peronismo clásico"). En efecto, la renovación historiográfica en la Argentina del retorno a la democracia no se había encargado del estudio de este período, dejándolo en manos de sociólogos, politólogos o ensayistas. Esto fue así en parte porque la agenda de investigación -en consonancia con la agenda política del alfonsinismo, que proponía una superación del peronismo en un "tercer movimiento histórico" - también se había propuesto "desperonizar" nuestra historia política, buscando las claves políticas, económicas y sociales de la Argentina de entonces en un pasado más remoto. ${ }^{15} \mathrm{En}$

${ }^{13}$ El uso de estas fuentes, así como de las preguntas que les hacemos, es tributario de la llamada "nueva historia legal" latinoamericana, expresión historiográfica de un campo interdisciplinario conformado en las últimas décadas al calor de influencias teóricas diversas (de Foucault a Cliford Geertz, pasando por reelaboraciones de Gramsci en E.P. Thompson y los Subaltern Studies) y de la centralidad que cobraron los sistemas judiciales latinoamericanos desde las transiciones democráticas de los años ochenta. Estos trabajos consideran a la instancia judicial como arena de conflicto social, en donde se dan cita y se confrontan diversos discursos y culturas legales (estatales y de la sociedad civil, positivas y consuetudinarias, letradas y legas, nacionales y locales) y como un mirador privilegiado de las relaciones sociales, que permite escuchar las "voces subalternas", difícilmente audibles en otras fuentes, oficiales o privadas: CANDIOTI, Magdalena e PALACIO, Juan Manuel. "Justicia política y derechos en América Latina. Apuntes para un diálogo interdisciplinario". En: (Eds.): Justicia, política y derechos en América Latina. Buenos Aires: Prometeo, 2007, pp. 11-24.

${ }^{14}$ FORTES, Alexandre ET ALLI. Na luta por direitos: estudos recentes em história social do trabalho. Campinas: Ed. da Unicamp, 1999; MARQUES MENDES, Alexandre. Classe Trabalhadora e Justiça do Trabalho: experiências, atitudes e expressões do opérario do calçado. Dissertação, Universidad Estadual Paulista, 2005; FORTES, Alexandre. Nós do Quarto Distrito. A classe trabalhadora porto-alegrense e a era Vargas. Rio de Janeiro: EDUCS, 2004; TEIXEIRA DA SILVA, Fernando. A carga e a culpa: os operários das docas de Santos. Direitos $e$ cultura de solidariedade, 1937-1968. São Paulo: Hucitec, 1995; WELCH, Cliff. The seed was planted: the São Paulo roots of Brazil's rural labor movement, 1924-1964. University Park: The Pennsylvania State Univ. Press., 1999; VARUSA, Rinaldo J. Trabalho e legislação: experiências de trabalhadores na Justiça do Trabalho (Jundiaí SP, décadas de 40 a 60). Ph.D. Dissertation, Pontifícia Universidade Católica/São Paulo, 2002.

${ }^{15}$ Además de la superación (política e historiográfica) del peronismo en nuestra historia, esta búsqueda de continuidades se fundaba en los nuevos aires epistemológicos, que tendían a desconfiar de los cortes abruptos y fundacionales, para reemplazarlos por procesos de más larga duración. De la mano de esta sospecha, distintos estudios realizados en esos años se fueron encargando de escribir historias más largas de todos aquellos aspectos que supuestamente daban al peronismo su carácter fundador y revolucionario, como sus 
particular, la historia política de los trabajadores (o de los "sectores populares", como prefería denominárselos) se reescribió con la mirada puesta en las tesis de Gino Germani acerca del apoyo incondicional que las "masas disponibles" dieron a Perón en 1945. Estos estudios prefirieron en cambio rastrear dicho apoyo en una larga tradición cultural preexistente entre los sectores populares, que incluía una historia también larga de prácticas asociativas y cooperativas construidas en sociedades de fomento, bibliotecas populares, clubes y asociaciones étnicas, que estaban en la base de su identidad y su experiencia política, que era previa al peronismo. ${ }^{16}$ En una clave parecida, las investigaciones de la "nueva historia política", centradas en los orígenes de la ciudadanía y la esfera pública, se preocupaban por dejar bien en claro que la historia de la movilización política se remontaba mucho más allá de Perón, incluso más allá de las manifestaciones obreras de las décadas anteriores a él. ${ }^{17}$

El derrumbe del alfonsinismo a fines de los ochenta y el advenimiento del menemismo volvió a cambiar la agenda de investigación historiográfica. El doble desengaño - con la democracia y con la posibilidad de neutralizar la hegemonía política del peronismoplanteaba a los historiadores a la vez una paradoja y una tarea. Una paradoja porque, más allá de la convicción, construida con genuina evidencia histórica, de que el peronismo no había sido todo lo revolucionario que su retórica pretendía, los acontecimientos políticos y electorales volvían a poner a ese partido en el centro de la escena como algo verdaderamente excepcional. Una tarea, ya que esos mismos sucesos políticos ponían nuevamente en evidencia que, más allá de que el peronismo reconociera antecedentes muy sólidos en la historia, era necesaria una indagación profunda en los años de los gobiernos de Perón si se querían encontrar muchas de las claves de la Argentina del siglo XX. ${ }^{18}$

De manera que desde hace apenas unos quince años los historiadores han comenzado a llenar, ahora sí, ese curioso vacío historiográfico, de la mano de acercamientos teóricos y metodológicos novedosos como los señalados más arriba. Se han multiplicado así trabajos que abordan la dimensión regional, provincial y local del peronismo; ${ }^{19}$ la

políticas sociales, el intervencionismo estatal en materia económica, etc. Una reflexión más extensa sobre este punto en PALACIO, Juan Manuel. "Historias de fin de siglo: notas sobre la historiografía argentina de las últimas décadas". En: Revista de Historia (San José de Costa Rica), 48, 2006, pp. 111-154.

${ }^{16}$ ROMERO, Luis Alberto. "Los sectores populares como sujetos históricos". En: Proposiciones (Santiago), 1, 1990, pp. 268-278; GUTIÉRREZ, Leandro e ROMERO, Luis Alberto. Sectores populares, cultura y política. Buenos Aires en la entreguerra. Buenos Aires: Sudamericana, 1989.

${ }^{17}$ SABATO, Hilda. La política en las calles. Entre el voto y la movilización. Buenos Aires, 1862-1880. Buenos Aires: Sudamericana, 1998; __. "On Political Citizenship in Nineteenth-Century Latin America”. En: American Historical Review, 106, 4, 2001, pp. 1290-1315.

${ }^{18}$ Nadie entendió mejor esa paradoja y esa tarea que Tulio Halperín Donghi - por otra parte, uno de los referentes obligados para esa generación de historiadores- quien en 1994 volvía a postular sin inmutarse el carácter revolucionario del peronismo y a interpretar la historia del país de la segunda mitad del siglo en esa clave. HALPERÍN DONGHI, Tulio. La larga agonía de la Argentina peronista, Buenos Aires: Ariel, 1994.

${ }^{19}$ MACOR, Darío e TCACH, César (Eds.). La invención del peronismo en el interior del país. Santa Fe: Universidad del Litoral, 2003; Melon Pirro, Julio César e Quiroga, Nicolás (Eds.). El peronismo bonaerense: Partido y prácticas políticas 1946-1955. Mar del Plata: Ediciones Suárez, 2006; QUIROGA, Nicolás. "El Partido Peronista en Mar del Plata: articulación horizontal y articulación vertical, 1945-1955". En: Boletín del Instituto de Historia 
conformación y el funcionamiento de la nueva burocracia estatal; ${ }^{20}$ algunas políticas públicas menos estudiadas, como las de salud ${ }^{21}$, inmigración ${ }^{22}$, industriales ${ }^{23}$, de vivienda ${ }^{24} \mathrm{y}$ género $^{25}$; la relación con la prensa ${ }^{26}$, el cine ${ }^{27}$, la iconografía ${ }^{28}$, entre otros.

Dentro de esta proliferación de acercamientos monográficos, la relación del peronismo con el mundo del trabajo ha sido una línea de investigación más entre otras -y no la más transitada- de manera que algunas de las discusiones clásicas sobre obreros nuevos y viejos, o sobre el sindicalismo y el apoyo a Perón ${ }^{29}$ no han sido revisitadas o no han estado en el centro de las preocupaciones (como según se verá, es el caso de la historiografía brasileña reciente). Existen sí, trabajos enfocados en la experiencia cotidiana de trabajadores durante el peronismo -en línea con las preocupaciones de Daniel James ${ }^{30}$ - como su participación en las "unidades básicas" -locales partidarios del partido peronista ${ }^{31}$; sobre la

Argentina y Americana "Dr. Emilio Ravignani" (Buenos Aires), 26, 2004, pp. 75-110; PANELLA, Claudio (ed.). EI gobierno de Domingo Mercante en Buenos Aires (1946-1952). Un caso de peronismo provincial. La Plata: Archivo Histórico de la Provincia de Buenos Aires, 2005; AELO, Oscar. "Apogeo y ocaso de un equipo dirigente: el peronismo en la Provincia de Buenos Aires, 1947-1951". En: Desarrollo Económico, 44, 73, 2004, pp. 85-107.

${ }^{20}$ BERROTARÁN, Patricia. Del plan a la planificación. El Estado durante la época peronista. Buenos Aires: Imago Mundi, 2003; BERROTARÁN, Patricia. "Educar al funcionario: 'de la frialdad de las leyes a las innovaciones doctrinarias' (Argentina 1946-1952)". En: Nuevo Mundo Mundos Nuevos, $2008 . \quad$ URL: http://nuevomundo.revues.org/36602 (16/06/2008); CAMPIONE, Daniel. Prolegómenos del peronismo. Los cambios en el estado nacional, 1943-1946. Buenos Aires: FISyP, 2003.

${ }^{21}$ RAMACIOTTI, Karina. La política sanitaria del peronismo. Buenos Aires: Biblos, 2009.

${ }^{22}$ BIERNAT, Carolina. ¿Buenos o útiles? La política inmigratoria del peronismo. Buenos Aires: Biblos, 2007.

${ }^{23}$ BELINI, Claudio. La industria peronista 1946-1955: políticas públicas y cambio estructural. Buenos Aires: Edhasa, 2009.

${ }^{24}$ ABOY, Rosa. Viviendas para el pueblo: espacio urbano y sociabilidad en el barrio Los Perales, 1946-1955. Buenos Aires: Fondo de Cultura Económica, 2005; Ballent, Anahi. Las huellas de la política: vivienda, ciudad y peronismo en Buenos Aires. Buenos Aires: UNQ - Prometeo, 2005.

${ }^{25}$ RAMACIOTTI, Karina y Adriana Valobra. Generando el peronismo. Estudios de cultura, política y género (19461955). Buenos Aires: Proyecto editorial, 2004; BARRY, Carolina et al (Eds.). La Fundación Eva Perón y las mujeres: entre la provocación y la inclusión. Buenos Aires: Biblos, 2008.

${ }^{26}$ REIN, Raan e PANELLA, Claudio (Eds.). Peronismo y prensa escrita: abordajes, miradas e interpretaciones nacionales y extranjeras. La Plata: Edulp, 2008; DA ORDEN, María Liliana e MELON PIRRO, Julio César (Eds.). Prensa y peronismo: discursos, prácticas y empresas, 1943-1958. Rosario: Prohistoria, 2007.

${ }^{27}$ KRIGER, Clara. Cine y peronismo: el estado en escena. Buenos Aires: Siglo XXI, 2009.

${ }^{28}$ GENÉ, Marcela. Un mundo feliz. Imágenes de los trabajadores en el primer peronismo. Buenos Aires: F.C.E, 2005.

${ }^{29}$ TORRE, Juan Carlos. La vieja guardia sindical y Perón: sobre los orígenes del peronismo. Buenos Aires: Sudamericana, 1990; DOYON, Louise. Perón y los trabajadores. Los orígenes del sindicalismo peronista, 19431955, Buenos Aires: Siglo XXI Editora Iberoamericana, 2006; MURMIS, Miguel y Juan Carlos Portantiero. Estudios sobre los orígenes del peronismo. Buenos Aires: Siglo Veintiuno, 1971, entre otros.

30 JAMES, Daniel. Resistencia e integración: el peronismo y la clase trabajadora argentina, 1946-1976. Buenos Aires: Sudamericana, 1990.

${ }^{31}$ QUIROGA, Nicolás. "El Partido Peronista en Mar del Plata: articulación horizontal y articulación vertical, 19451955". Op. cit.; ___. "Las Unidades Básicas durante el primer peronismo. Cuatro notas sobre el Partido Peronista a nivel local", op. cit. ACHA, Omar. "Sociedad civil y sociedad política durante el primer peronismo". En: Desarrollo Económico (Buenos Aires), 44, 174, 2004, pp. 199-230; BARRY, Carolina. Evita capitana. El Partido Peronista Femenino 1949-1955. Buenos Aires: Eduntref, 2009; MELON PIRRO y QUIROGA, op. cit. 
participación de las mujeres en el movimiento político ${ }^{32}$, o sobre la especificidad de esas experiencias durante el peronismo, en trabajos de más amplio aliento. ${ }^{33}$

A través de estas variadas investigaciones, esta historiografía ha conseguido desmantelar muy eficazmente ese "constructo" Ilamado peronismo, que consideraban fabricado tanto por la retórica oficial del mismo peronismo en el poder como, luego, por la historiografía "oficial" peronista (y por el discurso político peronista contemporáneo). De la mano de un rico instrumental teórico y metodológico que ha servido bien este propósito deconstruccionista, se han encargado de desmenuzar al peronismo en diversas partículas (provincias, municipios, actores, políticas específicas, etc.) y de "desnmascarar" su autoproclamado carácter revolucionario y fundacional, enfatizando nuevamente las continuidades y sometiendo a sus gobiernos a ejercicios de confrontación entre dichos y hechos, entre mitos y realidades, entre discurso y práctica, para demostrar cuánto de realización, de "verdad" ha habido entre todo lo dicho y prometido. ${ }^{34}$

En cuanto a los usos de fuentes judiciales, si bien la nueva historia legal tiene buenos y variados representantes en la historiografía argentina, todavía son muy escasos los que han encontrado provechoso analizar estos expedientes en la revisión del primer peronismo. ${ }^{35}$ Es por eso que las instancias de resolución de conflicto creadas por el peronismo, tanto como el proceso que dio origen a los tribunales laborales (debates parlamentarios, en medios jurídicos y la prensa) constituyen, curiosamente o no, campos casi vírgenes para el análisis.

\section{La historiografía reciente sobre varguismo y populismo}

Aunque coincidente en su espíritu revisionista y probablemente en muchos de sus acercamientos teóricos y metodológicos, el caso de la historiografía brasileña sobre el varguismo es bien diferente al caso argentino, por diversos motivos.

\footnotetext{
${ }^{32}$ BARRY, Carolina. Evita capitana. Op. cit.

${ }^{33}$ LOBATO, Mirta. La vida en las fábricas. Trabajo, protesta y política en una comunidad obrera, Berisso (19041970). Buenos Aires: Prometeo libros-Entrepasados, 2001; - Historia de las trabajadoras en la Argentina (1869-1960). Buenos Aires: Edhasa, 2007. Existen ya algunos de reflexión historiográfica sobre esta nueva literatura sobre el peronismo. Véase Rein, Raanan et AL. Los estudios sobre el primer peronismo: aproximaciones desde el siglo XXI. La Plata: Instituto Cultural de la Provincia de Buenos Aires, 2009; BELINI, Claudio y ROUGIER, Marcelo (2006): “Los dilemas de la historiografía económica sobre el peronismo: certezas dudosas, vacíos persistentes. Aportes para la construcción de una agenda de investigación”. En: Jorge Gelman (Ed.): La Historia Económica Argentina en la Encrucijada. Balances y Perspectivas. Buenos Aires: Prometeo, pp. 351-372; PALACIO, Juan Manuel. "El primer peronismo en la historiografía reciente: nuevas perspectivas de análisis". En: Latinoamericana (Berlin), 39, 2010, pp. 255-266.

${ }^{34}$ GIRBAL-BLACHA, Noemí. Mitos y realidades en la Argentina Peronista (1946-1955). Bernal: Universidad Nacional de Quilmes, 2003.

${ }^{35}$ Algunas excepciones son BARRENECHE, Osvaldo. "Por mano propia. La justicia policial de la provincia de Buenos Aires en el primer peronismo". En: Sociohistórica (La Plata), 25, 2009, pp. 123-152; PALACIO, Juan Manuel. "De la paz a la discordia: El peronismo y la experiencia del Estado en la provincia de Buenos Aires (1943-1955)”. En: Desarrollo Económico, 49, 194, 2009, pp. 221-246.
} 
La historiografía reciente sobre el "populismo" brasileño - un período que abarca los distintos gobiernos de Vargas hasta su suicidio en 1954 y se extiende luego hasta la caída de Goulart en 1964-cobró renovado impulso hacia los años noventa luego de la experiencia del fuerte protagonismo de los trabajadores en el proceso de "Diretas Já", que sirvió de inspiración para trazar una historia crítica de la agencia de los trabajadores en el pasado. ${ }^{36}$ Este revisionismo -que a diferencia del caso argentino, estuvo sobre todo en manos de historiadores sociales del trabajo- se propuso discutir la tesis de la supuesta pasividad de los trabajadores en la historia de la consecución de derechos laborales, idea que subyacía tanto al discurso varguista -y al de la historiografía "oficial" - pero también a la del revisionismo de los teóricos brasileños del populismo, como Weffort o lanni. ${ }^{37}$

Hay aquí, entonces, una primera diferencia con las preocupaciones del revisionismo de la historiografía argentina. En Brasil, la discusión no sólo se entabla con el discurso varguista (y la historiografía que lo reproduce) - ese que daba a Vargas la paternidad de la legislación laboral en Brasil y a sus gobiernos como un punto de llegada en la historia de la adquisición de derechos sociales por parte de los trabajadores- sino también con los primeros críticos de esa visión, que postulaban que dichas leyes habían sido solamente un maquillaje, un engaño, un instrumento de manipulación y control cuyo principal objetivo era la desmovilización de los trabajadores. Para la historiografía actual, ambas visiones, contrapuestas en cuanto a la valoración del varguismo, coinciden sin embargo en que sus gobiernos "otorgaron" estas leyes a los trabajadores como una dádiva, que ellos ni reclamaban ni de cuyos beneficios eran del todo conscientes, atrapados como estaban en el aislamiento de las relaciones sociales tradicionales en el Brasil rural. En una versión similar a la interpretación de Germani sobre el peronismo, los teóricos del populismo brasileño brindaban una imagen pasiva de los obreros "nuevos", cuya organización y conciencia de clase fue construida desde arriba por un gobierno dadivoso. ${ }^{38}$

\footnotetext{
${ }^{36}$ Existen ya algunas reconstrucciones historiográficas de estos revisionismos. Véase por ejemplo TEIXEIRA DA SILVA, Fernando y DA COSTA, Hélio. "Trabalhadores urbanos e populismo: um balanço dos estudos recentes". En FERREIRA, Jorge (Ed.): O populismo e sua história: debate e crítica. Rio de Janeiro: Civilização Brasileira, 2001, pp. 205-271; FRENCH, John D. "The origin of corporatist state intervention in Brazilian industrial relations, 1930-1934: a critique of the literature". En: Luso-Brazilian review (Madison), 28, 2, 1991, pp. 13-26; "El auge de los estudios sobre el trabajo en Latinoamérica". En: Historia social (Valencia), 39, 2001, pp. 129-150; VARUSA, Rinaldo J. Legislação trabalhista e trabalhadores: algumas reflexões a partir da historiografia. En Tempo da Ciência No. 14, 2000; DE CASTRO GOMES, Angela Maria. "Reflexões em torno de populismo e trabalhismo". En: Varia historia (Belo Horizonte), 28, 2002, pp. 55-68; MCCREERY, David. "Gift of the devil". En: Social History, 33, 1, 2008, pp. 68-77; CARNEIRO ARAÚJO, Angela María (Ed.). Trabalho, cultura e cidadania: um balanço da história social brasileira. São Paulo: Arquivo Edgard Leuenroth, 1997.

${ }^{37}$ Estos últimos postulaban que el propósito detrás de la legislación trabalhista no era favorecer a los trabajadores -como pretendía el discurso varguista- sino cooptarlos y manipularlos para de esa manera mantenerlos bajo el control del Estado y prevenir cualquier movilización autónoma. Esta visión también subyace a algunos trabajos historiográficos más tempranos como en DE CASTRO GOMES, Angela Maria. Burguesia e Trabalho. Política e legislaçao social no Brasil 1917-1937. Rio de Janeiro: Editora Campus Ltda, 1979; MUNAKATA, Kazumi. A Legislação trabalhista no Brasil. São Paulo: Brasiliense, 1982; VARUSA, Rinaldo J. Legislação trabalhista e trabalhadores: algumas reflexões a partir da historiografia. En Tempo da Ciência No. 14, 2000.

${ }^{38}$ Interpretación que se origina en los mismos escritos de los hacedores de esas leyes, como Oliveira Vianna.
} 
El revisionismo reciente disputa estas ideas desde varios lugares. Primero, al igual que ocurre en la historiografía argentina, estos trabajos postulan que la historia de las luchas de los trabajadores por sus derechos sociales no nace con Vargas, en 1930, ya que hay una historia más larga de sus luchas durante la Primera República, sin las cuales no pueden entenderse sus acciones ni actitudes frente al varguismo. Estas experiencias previas fueron clave en el grado de autonomía con que pudieron manejarse en esos años. ${ }^{39}$ Segundo, aún cuando las múltiples leyes "trabalhistas" y los organismos para regular el trabajo organizados durante los gobiernos de Vargas hayan sido creados con el propósito primordial de controlar a los trabajadores y sindicatos y de disipar el conflicto de clases, y aún cuando se hayan dado en un contexto autoritario y represivo, proveyeron un espacio de acción para los trabajadores, que éstos supieron aprovechar cada vez que tuvieron la oportunidad. ${ }^{40}$ Esto no sólo implicó generar una conciencia legal sobre sus nuevos derechos ${ }^{41}$ sino que se transformó en prácticas concretas en los ámbitos judiciales, aún cuando -según sostienen muchos trabajos- éstos eran espacios de limitación y control, antes que favorables a los trabajadores. ${ }^{42}$ Tercero, el hecho de que los derechos fueran consagrados en leyes contradice la idea misma de la dádiva, ya que lo que hace la ley es consagrar esos derechos en otro nivel, más formal y definitivo, que si bien no está exento de disputas y negociaciones, le otorga un carácter más definitivo al "pacto populista". Cuarto, sumado a lo anterior, los derechos no habrían sido otorgados porque, aún cuando los organismos fueron

${ }^{39}$ FRENCH, John D. "The origin of corporatist state intervention in Brazilian industrial relations, 1930-1934: a critique of the literature". En: Luso-Brazilian review (Madison), 28, 2, 1991, pp. 13-26; FRENCH, John D. The Brazilian worker's ABC: class conflict and alliances in modern São Paulo. Chapel Hill \& London: The Univ. of North Carolina Press, 1992; DE CASTRO GOMES, Angela Maria. A Invenção do trabalhismo. Rio de Janeiro: IUPERJ/Vértice, 1988; WOLFE, Joel. Working women, working men: São Paulo and the rise of Brazil's industrial working class, 1900 - 1955. Durham \& London: Duke Univ. Press, 1993, entre otros.

${ }^{40}$ Buscando reestablecer el protagonismo de los trabajadores en la historia política de Brasil, algunos autores postularon que, más que una manipulación, lo que existió fue más bien un pacto entre el estado populista y los trabajadores, pacto que los trabajadores hicieron estratégicamente a favor de sus intereses, dando un "consenso activo", un apoyo crítico -no incondicional- a Vargas (entre otros, DE CASTRO GOMES, 1988 y FRENCH, 1991 y 1992). Esta tesis es fuertemente discutida por WOLFE, Joel. Working women, working men... op. cit. y__ "The Faustian Bargain Not Made: Getúlio Vargas and Brazil's Industrial Workers, 1930-1945". En: Luso-Brazilian Review, 31, 2, 1994, pp. 77-95.

${ }^{41}$ FRENCH, John D. Drowning in laws: labor law and Brazilian political culture. Chapel Hill: Univ. of North Carolina Press, 2004; FERREIRA, Jorge. "Queremismo, trabalhadores e cultura política. Soberania popular e aprendizado democrático". En: Varia historia (Belo Horizonte), 28, 2002, pp.69-84; PAOLI, Maria Célia. Labor, law and the State in Brazil:1930-1950. Tesis doctoral, University of London, 1988.

42 MARQUES MENDES, Alexandre. Op. Cit.; VARUSA, Op. Cit.; Morel, Regina Lucia M. / Mangabeira, Wilma. "'Velho' e 'Novo' Sindicalismo e Uso da Justiça do Trabalho: Um Estudo Comparativo com Trabalhadores de Compañía Siderúrgica Nacional". En: Dados (Rio de Janeiro), 37,1, 1994, pp. ; TEIXEIRA DA SILVA, Fernando. $A$ carga e a culpa: os operários das docas de Santos. Direitos e cultura de solidariedade, 1937-1968. São Paulo: Hucitec, 1995. Existe en este punto un debate no resuelto entre los autores, ya que mientras unos, como French, ven a las instancias de resolución de conflictos (las Juntas de Conciliación primero, la JT después) como lugares en los que se burlaban sistemáticamente los derechos de los trabajadores -que por lo tanto preferían no acudir a ellos- para otros fueron un espacio más imprevisible en el que se podían ganar pleitos y por lo tanto eran frecuentemente utilizados por los trabajadores. VARUSA, IDEM y VARUSA, Rinaldo J. Trabalho $e$ legislação: experiências de trabalhadores na Justiça do Trabalho (Jundiaí - SP, décadas de 40 a 60). Ph.D. Dissertation, Pontifícia Universidade Católica/Sao Paulo, 2002; TEIXEIRA DA SILVA, Fernando. Op. Cit. 
diseñados para controlar y limitar la acción de los trabajadores, éstos con sus acciones rebasaron esos límites, disputando, burlando esas intenciones, y usando esas leyes y organismos a su favor, en la línea de lo planteado por E.P. Thompson para Inglaterra. ${ }^{43}$

Este revisionismo también llevó -como en el caso argentino- a una reevaluación de las cronologías vigentes sobre la historia de los trabajadores en Brasil. En un primer momento, a fines de los años setenta y principios de los ochenta del siglo pasado, en el contexto de la experiencia de las luchas de los trabajadores durante los gobiernos militares y en el contexto académico de auge de los estudios de "esfera pública" y ciudadanía- la historiografía pareció interesarse más por los años de la Primera República -y por los posteriores a 1964- como momentos de acción "autónoma" de los trabajadores, siendo el período "populista" en cierta medida relegado, por considerárselo como uno de pasividad y de heteronomía de las clases trabajadoras y por lo tanto menos interesante para el análisis. Más recientemente y bajo una nuevas luces teóricas y metodológicas, los años del varguismo están siendo revalorizados, con investigaciones que buscan identificar espacios de agencia y de acción autónoma de los trabajadores durante los años populistas. ${ }^{44}$

De esta manera, la historiografía brasileña reciente -en una de las diferencias más notorias con la argentina, que prefiere evitarlo ${ }^{45}$ - decide entonces discutir la categoría del "populismo", historizando algunos de sus supuestos fundamentales, como el de la pasividad y la heteronomía de las clases subalternas durante ese período, la ruptura que significó el varguismo en la historia de las clases trabajadoras, el apoyo incondicional al líder, la falsa consciencia de clase y la idea misma del pacto populista. Buena parte de esa revisión está basada en el análisis de las experiencias de los trabajadores frente a diferentes instancias estatales, en particular en el estudio la justicia del trabajo, a través de los expedientes judiciales, lo que marca otra característica distintiva de la historiografía revisionista brasileña. La cantidad y calidad de investigaciones llevadas a cabo en esta línea pone a esa historiografía en un lugar diferente en el contexto latinoamericano.

\section{La historiografía de la Revolución Mexicana y el Cardenismo}

Obtener una visión de conjunto del caso de México y su historiografía reciente sobre estos temas es más problemático. Primero porque la dinámica de crecimiento de la historiografía de la Revolución -ese campo historiográfico que por su envergadura no tiene paralelo en la historiografía latinoamericana- hace que el capítulo de la historia laboral sea

\footnotetext{
${ }^{43}$ En ese sentido, parecería que en Brasil los trabajadores tuvieron un papel mucho más importante en la efectiva aplicación de los nuevos derechos que en la Argentina (y para el caso, México).

${ }^{44}$ TEIXEIRA DA SILVA, Fernando e DA COSTA, Hélio. "Trabalhadores urbanos e populismo: um balanço dos estudos recentes". En FERREIRA, Jorge (Ed.): O populismo e sua história: debate e crítica. Rio de Janeiro: Civilização Brasileira, 2001, pp. 205-271.

${ }^{45}$ Con la posible excepción de REIN, Raanan. Peronismo, populismo y política: Argentina, 1943-1955. Buenos Aires: Editorial de Belgrano, 1998.
}

Revista Mundos do Trabalho, vol. 3, n. 5. 
sólo eso, un capítulo dentro de un revisionismo que además no ha tenido descanso casi desde la Revolución misma. ${ }^{46} \mathrm{El}$ otro punto problemático es que, fuera de algunos trabajos que lo han postulado enfáticamente ${ }^{47}$ no existe un consenso tan amplio ni en México ni entre los teóricos principales del populismo en considerar al gobierno de Cárdenas como un ejemplo paradigmático del "populismo clásico" latinoamericano. ${ }^{48} \mathrm{El}$ tercer punto problemático es que esas medidas que se señalaron en el apartado anterior (aprobación de leyes laborales y nuevos organismos de intervención y regulación del mercado de trabajo), se dieron en México en un proceso más gradual, desde el inicio de la Revolución, en 1910. De manera que, si bien son bastante similares tanto en su letra como en su espíritu, la tendencia "obrerista" de la Revolución Mexicana existe desde sus primeros años, más allá de que en algunos aspectos Cárdenas pueda haberlas radicalizado. ${ }^{49}$ Son más bien los gobiernos de Calles y del denominado Maximato los que exhiben concreciones decisivas en materia legal e institucional en la regulación del trabajo, como la resolución citada de la Corte Suprema de 1924, dando fuerza de ley a las Juntas de Conciliación y Arbitraje, la creación del Sistema Nacional de Arbitraje (1927) y, sobre todo, con la aprobación de la Ley Federal del Trabajo, en 1931.

En cuanto a la literatura específica sobre los trabajadores y su relación con las nuevas leyes e instituciones estatales, no es mucho lo que se ha escrito en los últimos años y el grueso de lo nuevo se ha producido en la academia norteamericana, siendo el trabajo de del politólogo Kevin Middlebrook, The Paradox of Revolution, ${ }^{50}$ una referencia obligada. Allí, este autor -para quien la entrada de los trabajadores en la política nacional representa la consecuencia de largo plazo más significativa de la Revolución- realiza un estudio detallado del proceso de conformación de las instituciones laborales del estado revolucionario (del Departamento de Trabajo a la Secretaría de Trabajo y Previsión Social) y en particular de la evolución histórica de las Juntas de Conciliación y Arbitraje, en el marco del trabajoso proceso de consolidación del estado federal.

Otros trabajos se han concentrado también en los procesos de implementación en los distintos estados del artículo 123 de la Constitución de 1917, enfatizando las resistencias que generó en la política y la sociedad locales. ${ }^{51}$ Estos trabajos, como era el caso de algunos

${ }^{46}$ KNIGHT, Alan. “Interpretaciones recientes de la revolución mexicana”. En: Secuencia (México), 13, 1989, pp. $23-43$.

${ }^{47}$ v.g., HAMILTON, Nora. México: los límites de la autonomía del estado. México: Era, 1983; CÓRDOVA, Arnaldo. La política de masas del Cardenismo, México: Era, 1974.

${ }^{48}$ FALCÓN, Romana. "El surgimiento del agrarismo cardenista: Una revisión de las tesis populistas". En: Historia Mexicana (México), 27, 3, 1978, pp. 333-386.

${ }^{49}$ De hecho, la radicalización del populismo de Cárdenas, según Hamilton, pasa más por sus acciones en materia rural -con la extensión inédita de la reforma agraria y la organización de la Confederación Nacional Campesina- que por sus innovaciones en materia de organización del trabajo.

${ }^{50}$ MIDDLEBROOK, Kevin J. The paradox of revolution : labor, the State, and authoritarianism in Mexico. Baltimore \&London: Johns Hopkins Univ. Press, 1995.

${ }^{51}$ BENSUSÁN, Graciela. "La legislación heredada de las luchas revolucionarias: del constituyente a la Ley Federal del Trabajo". En: MORENO TOSCANO, Alejandra y LEÓN GONZÁLEZ, Samuel: 75 años de sindicalismo mexicano. México: Inst. Nacional de Estudios Históricos de la Revolución Mexicana, 1986; . La ley federal 
en la historiografía brasileña, se concentran sobre todo en el rol de la Ley Federal del Trabajo (y de las Juntas de Conciliación) en el control del movimiento obrero organizado y en su espíritu esencialmente desmovilizador, estudiando en particular la dinámica de conflictos que generaba la implementación de una legislación nacional del trabajo (la resistencia de las elites y los gobiernos estaduales, la discusión política y jurídica del problema federal, etc.). También se concentran en el rol de las Juntas en la reglamentación local de los sindicatos (fijación del contrato-ley, reconocimiento legal, etc.) y en la resolución de conflictos colectivos, mientras que escasean los trabajos sobre los usos individuales de estas instancias por parte de los trabajadores.

Excepciones a estas tendencias son los trabajos de Jeffrey Bortz, ${ }^{52}$ que sostiene la tesis de una "revolución de los trabajadores" dentro de la Revolución, desatendida por la historiografía, que sin embargo fue decisiva en el armado del estado revolucionario y derivó en que México tuviera las leyes laborales más completas y progresistas del mundo occidental de entonces. Más recientemente, William Suarez-Potts estudió la actuación de la Corte Suprema y las Juntas de Conciliación y Arbitraje en México desde 1917, como un intento de "judicializar" las relaciones del trabajo por parte de los gobiernos de la Revolución, en un trabajo donde se plantea cuestiones similares a algunos de los trabajos escritos para Brasil y Argentina. ${ }^{53}$ Así, Suarez-Potts ve a las Juntas como espacios de oportunidad para desplegar discursos de derechos y formulaciones legales, en definitiva, para ir creando una gimnasia legal y procesal en la defensa de sus derechos.

Dichas estas salvedades, el período cardenista no ha estado ausente de revisionismos en los últimos años. En particular, a tono con el camino que ya había señalado Alan Knight, ${ }^{54}$ algunos trabajos están poniendo en cuestión tanto la supuesta coherencia interna y fortaleza del estado cardenista como la eficacia con que logró asentar la autoridad del gobierno central en todo México. Nuevamente aquí las novedades vienen de la mano de historiadores norteamericanos, con estudios sobre las diversas vicisitudes que tuvo la implementación de la políticas cardenistas en los estados de Sonora ${ }^{55}$ y Yucatán. ${ }^{56}$ Con

del trabajo: una visión retrospectiva. Los intentos de reglamentación local del artículo 123 (1917 - 1929). México: Fundación Friedrich Ebert. (Documentos de trabajo, Fundación Friedrich Ebert, No. 24), 1989; __. El modelo mexicano de regulación laboral. México: Plaza y Valdéz, 2000; MONTES DE OCA NAVAS, Elvia. Política laboral y corporativismo en el Estado de México 1934-1940. Zinacantepec: El Colegio Mexiquense \& Inst. Tecnológico y de Estudios Superiores de Monterrey, 2000.

52 BORTZ, Jeffrey. "The genesis of the Mexican labor relations system: federal labor policy and the textile industry 1925-1940". En: The Americas (Washington), 52,1, 1995, pp. 43-69, y especialmente BORTZ, Jeffrey. Revolution within the revolution: cotton textile workers and the Mexican labor regime, 1910-1923. Stanford: Stanford Univ. Press, 2008.

${ }^{53}$ VARUSA, Rinaldo J. Trabalho e legislação... Op. cit; TEIXEIRA DA SILVA, Fernando. A carga e a culpa... op. cit.; PALACIO, Juan Manuel. "De la paz a la discordia: El peronismo y la experiencia del Estado en la provincia de Buenos Aires (1943-1955)". En: Desarrollo Económico, 49, 194, 2009, pp. 221-246, entre otros.

${ }^{54}$ KNIGHT, Alan. “Cardenismo: ¿coloso o catramina?”. En: MACKINNON, Moira y PETRONE, Mario (Eds.): Populismo y neopopulismo en América Latina. El problema de la Cenicienta. Buenos Aires: Eudeba, 1999, pp. 197-230.

${ }^{55}$ BANTJES, Adrian A. As if Jesus walked on earth: Cardenismo, Sonora, and the Mexican Revolution. Wilmington: Scholarly Resources, 1998. 
diferentes matices, ambos autores se interesan por los diversos significados del cardenismo y su funcionamiento cotidiano en los distintos estados y destacan las limitaciones y fragilidades que tenía estado federal para aplicar sus políticas -e incluso para ganarse el apoyo de sectores populares- en estos estados geográficamente lejanos del país.

\section{Algunas reflexiones generales y preliminares}

La lectura de la historiografía reciente sobre los llamados regímenes populistas latinoamericanos "clásicos" o "primeros" permite extraer algunas conclusiones:

1. El ejemplo de la historiografía brasileña indica que el abordaje del "fenómeno" o "momento" populista por parte de los historiadores es a todas luces productivo y debería ser imitado. Así como ocurrió en su momento con la "teoría de la dependencia" -que a partir de los años ochenta la historiografía latinoamericana sometió a dura crítica, cuestionando la mayoría de sus simplificaciones y buscando ubicar en contextos históricos y nacionales precisos sus generalizaciones- es necesario reinterpretar al populismo a la luz de las experiencias históricas concretas, sin desecharlo del todo a favor de una fragmentación que renuncie a interpretaciones más generales, sino rescatando su capacidad explicativa. En ese sentido, no hay dudas de la especificidad de ese momento en la historia de estas naciones aquí consideradas - un momento que ha sido y sigue siendo clave en su vida política, social y económica, así como en la historia de la construcción del Estado.

2. Dentro de ese revisionismo del populismo, la "entrada" a través de las fuentes judiciales es ciertamente prometedora, pues permite mejor que muchas otras acercarse vívidamente a la experiencia del Estado de los trabajadores y de otros actores sociales subalternos -una experiencia sobre la que se han construido muchas hipótesis y supuestos, pero que se ha investigado poco- así como a la historia menuda de las agencias estatales y de su construcción cotidiana, en su juego, siempre dinámico y disputado, con la sociedad civil. En estos aspectos, es nuevamente la historiografía brasileña la que lleva la delantera y sería muy aconsejable seguir sus pasos.

3. Las historiografías recientes aquí reseñadas, a pesar de su revisionismo, siguen sosteniendo una mirada más bien negativa sobre los populismos latinoamericanos y sus políticas obreristas. ${ }^{57}$ En efecto, los nuevos trabajos parecen confirmar la tesis de los

\footnotetext{
${ }^{56}$ FALLAW, Ben. Cárdenas compromised: the failure of reform in postrevolutionary Yucatán. Durham \& London: Duke Univ. Press, 2001.

${ }^{57}$ Una buena interpretación sobre la antipatía generalizada de intelectuales y cientistas sociales -de izquierda y de derecha- con el fenómeno populista, en la introducción de MacKinnon y Petrone a su recopilación de textos
} 
teóricos clásicos del populismo que sostenía que la intención primera de estos regímenes al promover leyes sociales fue la desmovilización y el control de los trabajadores. ${ }^{58}$ Frente a eso -y esto es lo novedoso en la mirada del último revisionismo- los trabajadores hicieron valer sus derechos gracias a sus luchas y a los usos que hicieron de esas "dádivas engañosas". En otras palabras, dichos logros se consiguieron a pesar de los gobiernos populistas y sus instrumentos de control y no gracias a ellos. Este rasgo interpretativo es más claro para los casos de las historiografías brasileña y mexicana y menos para la argentina, en donde hay una mirada más "positiva" sobre las leyes sociales del primer peronismo y sobre la toma de posición de Perón por los trabajadores, en su desafío a las clases dominantes. ${ }^{59}$

4. Una posible explicación de lo anterior podría residir en el hecho de que los estudios que se han basado en los archivos de los nuevos organismos reguladores del trabajo se han concentrado sobre todo en los conflictos colectivos, en donde jugaban más las cuestiones políticas y en donde el estado nacional normalmente tenía que negociar con las resistencias a veces muy poderosas de los intereses de las burguesías o los gobiernos locales (v.g., frente a la posibilidad de una huelga o del reconocimiento de un sindicato). Es así como estudios basados en expedientes de las juntas de conciliación (tanto en Brasil como en México) suelen mostrarnos al representante del Estado habitualmente del lado de los patrones más que del de los trabajadores y por lo tanto a dichos organismos estatales esencialmente como instrumentos de control y de desmovilización de las clases trabajadoras. En ese sentido, es posible que trabajos basados en el análisis de acciones individuales de los trabajadores ante estos organismos -menos organizadas y por cuestiones más menudas y cotidianas- puedan contribuir a matizar esa imagen negativa que se tiene sobre estas Juntas. Dichas causas individuales -al menos, según se desprende del análisis del caso argentino- permiten ver en acción los discursos y estrategias judiciales que despliegan los diferentes actores en estas instancias, el aprendizaje cotidiano de saberes y tácticas procesales por parte de los subalternos o el rol fundamental de abogados y otros intermediarios burocráticos en la transmisión de dichos saberes. En otras palabras, permiten ver el efecto benéfico que tuvieron estos organismos para la construcción cotidiana de la "consciencia legal" de los trabajadores a la que se refería John French, más allá y a pesar de

clásicos sobre el populismo latinoamericano: MACKINNON, Moira y PETRONE, Mario (Eds.). Populismo y neopopulismo en América Latina. El problema de la Cenicienta, Buenos Aires: Eudeba, 1999.

${ }^{58}$ Hay excepciones a lo que se dice, que sólo confirman la regla. Véase FERREIRA, Jorge. Trabalhadores do Brasil. O imaginário popular. Rio de Janeiro: Fundaçao Getulio Vargas, 1997; DE CASTRO GOMES, Angela Maria. "Reflexões em torno de populismo e trabalhismo". En: Varia historia (Belo Horizonte), 28, 2002, pp. 55-68; BORTZ, Jeffrey. "The genesis of the Mexican labor relations system: federal labor policy and the textile industry 1925-1940". En: The Americas (Washington), 52,1, 1995, pp. 43-69; Revolution within the revolution : cotton textile workers and the Mexican labor regime, 1910-1923. Stanford: Stanford Univ. Press, 2008.

${ }^{59}$ La diferencia aquí puede no limitarse a la historiografía y también deberse a las especificidades de la experiencia histórica del peronismo en la Argentina. 
cuáles hayan sido las intenciones últimas o "verdaderas" detrás de la creación de estos organismos. $^{60}$

5. Como ocurría en los trabajos tradicionales, la nueva historiografía sobre el populismo sigue concentrándose marcadamente en el ámbito urbano e industrial y, dentro de él, en los centros urbanos más destacados, ya sean las capitales de los países o sus principales centros industriales. Y si bien se ha avanzado bastante en el análisis de la experiencia populista en las provincias o estados, también en esos casos en general se analiza lo ocurrido en ámbitos urbanos (las capitales o los principales pueblos dentro de los estados). Y esto es así, a pesar del hecho evidente de que esos regímenes se dan en sociedades esencialmente rurales (en particular la mexicana y la brasileña) y de que por lo tanto una parte decisiva del apoyo que recibían provenía de la población rural. Sin embargo, como de memoria -y a pesar de que todo indica que es éste un momento propicio para revisarlo- los trabajos recientes siguen privilegiando el análisis de la configuración urbana e industrial del "lazo populista". ${ }^{61}$

6. A pesar de las similitudes señaladas tanto en los hechos como en los relatos históricos recientes, se da la paradoja de que las historiografías sobre el tema siguen ignorándose mutuamente. Y esto es así, a pesar de la coincidencia de los procesos de producción de leyes y organismos estatales sobre la cuestión laboral en todos los países (que a veces llevan nombres prácticamente idénticos); a pesar de la contemporaneidad en que se dan; a pesar de las fuentes y acercamientos comunes que están realizando los historiadores a estos períodos; $y$, fundamentalmente, también a pesar de los múltiples contactos que una mirada rápida a diversas fuentes (escritos de juristas y parlamentarios contemporáneos, debates en la prensa y las revistas especializadas de la época) revela que existían entre los actores contemporáneos en los distintos países. ${ }^{62}$ La impresión que dejan las fuentes es que

\footnotetext{
${ }^{60}$ En efecto, en las fuentes judiciales en las que se basa el proyecto en curso para el caso argentino (que son principalmente conflictos individuales), la presunción que puede hacerse sobre los representantes estatales es exactamente la opuesta a la que se postula para los casos mexicano y brasileño. Tanto en las Juntas como en las Cámaras de Conciliacion y Arbitraje se encuentra a los representantes estatales casi siempre a favor del trabajador, cosa que sabían bien tanto los empleadores -que trataban de eludir esa instancia- como por supuesto los mismos trabajadores.

${ }^{61}$ En México hay que hacer la excepción de los múltiples estudios sobre la implementación de la reforma agraria en los distintos estados. Aunque los instrumentos de construcción de hegemonía del estado revolucionario mexicano eran otros -la incorporación de campesinos y trabajadores rurales en la administración de los ejidos, los bancos ejidales, la confederación Nacional Campesina y finalmente el Partidoson de alguna manera análogos a la legislación social en su rol clave en la conformación de ese "lazo". Una excepción para el caso de Brasil es el trabajo de CLIFF, Welch. The seed was planted: the São Paulo roots of Brazil's rural labor movement, 1924-1964. University Park: The Pennsylvania State Univ. Press, 1999.

${ }^{62}$ Así por ejemplo, la circulación de ideas que existía en el mundo sobre temas de leyes y justicia laboral durante esos años, que no sólo llegaban a las intelligentzias de cada país -a los ideólogos de las nuevas leyes y a los altos funcionarios del estado- sino también a los juristas (v.g. cuando uno observa a Oliveira Vianna citando al argentino Bielsa o al mexicano De la Cueva o viceversa). También, los presidentes Vargas, Perón y Cárdenas solían enviar representantes a los encuentros periódicos que sostenía la Organización Internacional
} 
esta circulación de ideas, de personas, de debates, de proyectos -que se concebían casi siempre en diálogo y con la mirada atenta hacia otras experiencias de la región- era tan corriente y fluida, que podría decirse que el aislamiento, la indiferencia mutua, es una construcción (equivocada) de nuestras historiografías, que la experiencia histórica contradice. Si esto es cierto, la mirada comparativa -cuya ausencia se suele lamentar para otros temas también- sería en este caso una perspectiva ineludible, si se quiere realmente comprender un fenómeno que excedió en mucho lo nacional y se construyó en un contexto mayor -regional, pero también podría decirse occidental- sin el cual no es completamente inteligible.

\section{HIPÓTESIS DE TRABAJO}

1. Hablar de ley y justicia en el Estado populista puede parecer una contradicción en los términos. El sentido común académico indica que estos regímenes se han caracterizado por despreciar las instituciones, avasallar la división de poderes y gobernar de forma autoritaria por encima y a costa de la ley. Esa crítica parte de la constatación de las formas variadas en la que estos regímenes lesionaron algunos principios sagrados del estado liberal y en tal sentido no difieren mucho de las que estos gobiernos recibían de los mismos contemporáneos, en particular desde los sectores políticos que habían desplazado del poder. Inobjetable en un sentido, la crítica sin embargo pasa por alto que los populismos latinoamericanos fueron, en otro sentido, marcadamente institucionalistas y grandes creadores de derecho. En verdad, si algo quisieron fue crear una gigante estructura legal e institucional que conscientemente desafiara el viejo orden estatal liberal, cuyo punto culminante fueron las reformas constitucionales que emprendieron. La preocupación de las ciencias sociales por señalar el carácter autoritario, clientelista y fuertemente centralizador de estos gobiernos ha ocultado muy eficazmente este otro dato no menos evidente.

2. Adoptar esta perspectiva nos permitiría a los historiadores, por así decirlo, una salida elegante al que podríamos llamar el "paradigma de la aberración" con el que hemos venido analizando a estos regímenes. Desde esta otra óptica, no se trataría ya de gobiernos que avasallaron las instituciones, no respetaron la división de poderes, fueron autoritarios, etc. sino que (o si se quiere, junto con eso) propusieron una nueva institucionalidad que desafiaba abiertamente el orden jurídico e institucional del estado liberal.

del Trabajo. Todos estos contactos -a los que habría que agregar los que seguramente existían entre los movimientos obreros de estos países- constituyen también un espacio fecundo para la investigación. John French llama la atención sobre este punto en la entrevista "Pensar a América Latina" (véase FORTES et al, Op. cit., pp. 181-207) y dedica unas páginas de su libro Drowning in Laws a analizar este "campo jurídico" en Brasil. FRENCH, John D. Drowning in laws: labor law and Brazilian political culture. Chapel Hill: Univ. of North Carolina Press, 2004. 
3. El campo de batalla elegido para ese desafío fue precisamente el de la ley, la justicia y las instituciones. Los gobiernos Perón, Cárdenas y Vargas, entre otros, fueron en efecto grandes creadores de derecho. Tanto el aparato de intervención social como el más general de regulación minuciosa de la vida económica y social tuvo como eje la producción (la superproducción, podría decirse) de leyes, decretos, normas regulatorias, que probablemente si se contaran igualarían en número a las producidas en todos los gobiernos anteriores sumados.

4. La transformación legal e institucional que emprendieron estos regímenes no era algo improvisado y por el contrario era un proyecto largamente estudiado y cuidadosamente diseñado. Una mirada a los debates parlamentarios de las leyes laborales fundamentales en cualquiera de estos países -así como a los escritos de actores fundamentales como Oliveira Vianna o José Figuerola- hablan a las claras de que los impulsores de las leyes y de las instituciones laborales en estos países eran grandes juristas, estudiosos del derecho internacional, que además conocían los debates y las experiencias contemporáneos de otros países sobre el tema.

5. Junto con la creación de leyes, fueron piezas clave de ese gran proyecto de creación institucional las políticas en torno a la administración de justicia, en lo que a su vez representaba uno de los desafíos más grandes al orden liberal. El caso más conocido es el de la creación de tribunales laborales, que ocurre más o menos contemporáneamente en diversos países de América Latina. Junto con ellos, toda una variedad de organismos burocráticos con funciones judiciales pero controlados desde el Poder Ejecutivo (que podrían denominarse "parajudiciales", como las diversas juntas y cámaras de conciliación y arbitraje) cumplieron un rol clave en la aplicación de la nueva legislación económica, social y laboral, tanto de la preexistente a estos regímenes como muy en especial de la nueva legislación que esos mismos gobiernos se enorgullecían de presentar como revolucionaria e inédita.

6. Estas verdaderas políticas judiciales (que constituyen un aspecto todavía oscuro del ampliamente estudiado intervencionismo del estado populista) perseguían un objetivo central: quitar de su ámbito natural (el Poder Judicial) la potestad estatal de resolución de conflictos y pasarlos al ámbito del Poder Ejecutivo. En efecto, los nuevos organismos (las cámaras arbitrales, las juntas de conciliación, etc.), se ubicaban en paralelo o por encima de los tradicionales (justicia de paz, justicia civil), a los que se les quita buena parte de su jurisdicción. Esto tenía al menos tres ventajas: por un lado, permitía al Poder Ejecutivo controlar la aplicación de la nueva legislación social, eludiendo las imprevisibilidades de la vía judicial tradicional, garantizando que los conflictos contractuales y laborales se resolvieran en sus dependencias y según el espíritu de las nuevas leyes. Esto mismo permitía eludir el conservadurismo del poder judicial -quizás el bastión más resistente a las políticas 
de estos regímenes- que en particular era muy remiso a aceptar la aplicación del "nuevo derecho". Tercero, administrar justicia a través de estos organismos "parajudiciales" erigía al Poder Ejecutivo, al presidente de la nación, como el gran benefactor que, de una manera directa, hacía llegar los beneficios de la nuevas políticas sociales a los trabajadores y campesinos, de manera de que no hubiera ninguna duda de dónde residía a la vez la paternidad y la tutela de los nuevos derechos.

7. A través de la nueva legislación social y de los nuevos organismos y actores burocráticos, muchas veces desplegados en una red de delegaciones del Poder Ejecutivo distribuidas a lo largo del territorio nacional, el Estado nacional persiguió la efectiva aplicación de la ley a lo largo del territorio del país (algo que en sí mismo constituía una novedad para estos países, dados los importantes bolsones de autonomía que dejaban los "órdenes conservadores" anteriores) con el objetivo general de consolidar el poder del estado central pero también de hacer llegar los beneficios de las nuevas leyes sociales a los trabajadores y campesinos de toda la geografía nacional.

8. En tal sentido, y en la medida en que, en forma además muy publicitada, estos nuevos organismos "llegaban" a los diferentes pueblos de la geografía nacional para garantizar los nuevos derechos -ocupando y controlando espacios de conciliación y de resolución de conflictos- constituyeron un espacio inestimable de construcción cotidiana de hegemonía de éstos regímenes y transformaron sustancialmente las experiencias del estado de todos los actores sociales. En particular, el hecho de que los sectores subalternos (trabajadores, campesinos) de todos los rincones del país pudieran ganar pleitos en los tribunales laborales o ante las cámaras arbitrales frente a patrones o terratenientes, además de una experiencia novedosa, era una confirmación de que las promesas de estos gobiernos y de su legislación social y laboral parecían hacerse realidad. Esta constatación les granjeó a esos gobiernos el apoyo silencioso de los sectores populares en todo el país, más allá de los más visibles, publicitados y estudiados apoyos de los obreros industriales concentrados en las grandes ciudades.

9. Si lo anterior es cierto, el análisis de lo que podría denominar la "dimensión rural" del fenómeno populista latinoamericano -todavía descuidada por las ciencias sociales y la historiografia- podría ser fructífero. El mirador del mundo rural podría permitir acercarse a los procesos más subterráneos y cotidianos de la construcción de hegemonía a lo largo y a lo ancho de la geografía de cada uno de estos países -al hidden text del populismo, para utilizar la feliz expresión que Cliff Welch encontró para el Brasil rural bajo Vargas- cosa que, suponemos, fue una de sus características distintivas. Desde allí podríamos ponderar en toda su dimensión la eficacia de la implantación territorial del estado nacional en los distintos rincones del país. 
Recebido em 14/06/2011

Aceito para publicação em 31/07/2011 